\title{
Agalmatolito do Quadrilátero Ferrífero, MG
}

\section{Hanna Jordt-Evangelista ${ }^{1}$ \& Carlos Eduardo Reinaldo Delgado ${ }^{2}$}

\begin{abstract}
Resumo Agalmatolito é uma rocha peraluminosa de emprego industrial, essencialmente composta por pirofilita. Ocorrências e minas de agalmatolito encontram-se distribuídas em uma área de cerca de $350 \mathrm{~km}^{2}$ a noroeste da província mineral do Quadrilátero Ferrífero, Minas Gerais. Há diversos tipos de rochas comercialmente denominadas agalmatolito, compostas por outros minerais além da pirofilita, tais como moscovita, quartzo, cianita e andaluzita, que mostram substituição, em graus variáveis, por pirofilita e diásporo. Análises por MEV/EDS aliados à microscopia óptica e difração de raios X mostraram que é possível diferenciar moscovita de pirofilita pelas texturas, sendo que a pirofilita ocorre em massas de granulação extremamente fina e sem orientação preferencial, enquanto a moscovita constitui dois tipos texturais: palhetas de porte maior ou agregados de finíssimas placas fortemente orientadas. As encaixantes do agalmatolito que correspondem, em parte, ao protólito dessa rocha, são rochas metavulcânicas e metassedimentares interpretadas como pertencentes ao greenstone belt arqueano Rio das Velhas. As metavulcânicas são compostas por fenocristais relícticos de feldspato alcalino em matriz metamórfica de clorita, moscovita, epidoto e quartzo. As rochas metassedimentares são formações ferríferas bandadas, quartzitos e xistos com variáveis proporções de quartzo, moscovita, cianita, andaluzita, coríndon, granada, estaurolita, cloritóide, clorita, turmalinas e rutilo/leucoxênio. A associação estável de estaurolita e cloritóide permite estabelecer a temperatura do evento metamórfico regional, responsável pela formação das rochas encaixantes e do protólito do agalmatolito, em $\mathrm{T} \sim 500-550^{\circ} \mathrm{C}$. A transformação de cianita em andaluzita indica que houve queda da pressão para valores inferiores a $4 \mathrm{kbar}$, talvez ainda durante o metamorfismo regional. $\mathrm{O}$ agalmatolito foi formado em $\mathrm{T} \sim 350-400^{\circ} \mathrm{C}$, às custas de rochas metassedimentares peraluminosas, compostas por proporções variáveis de cianita, andaluzita, moscovita e quartzo. A pirofilita foi gerada por meio de reações hidrotermais em zonas de cisalhamento de possível idade transamazônica, que funcionaram como coletoras dos fluidos ricos $\mathrm{em}_{2} \mathrm{O}$.
\end{abstract}

Palavras-chave: agalmatolito, Minas Gerais, pirofilita, petrografia, petrogênese.

Abstract Agalmatolite from the Quadrilátero Ferrifero, $M G$. Agalmatolite is a peraluminous rock type of industrial use composed essentially of pyrophyllite. Northwest of the Quadrilátero Ferrífero mineral province in Minas Gerais, agalmatolite occurrences and mines are distributed over an area of about $350 \mathrm{~km}^{2}$. There are several rock types commercially named agalmatolite and which are made up of minerals other than pyrophyllite, such as muscovite, quartz, kyanite and andalusite showing variable degrees of replacement by pyrophyllite and diaspore. Analyses by SEM/EDS, optical microscopy and X ray diffraction showed that it is possible to distinguish pyrophyllite from muscovite by their distinct textures, pyrophyllite occurring as randomly oriented and extremely fine-grained masses, while muscovite constitutes two textural types: large flakes or fine-grained but always preferentially oriented aggregates. The country rocks, which at least in part correspond to the protolith of the agalmatolite, are metavolcanic and metasedimentary rocks interpreted as belonging to the archean Rio das Velhas greenstone belt. The metavolcanic rocks are composed of relict phenocrysts of alkali-feldspar in a metamorphic matrix of chlorite, muscovite, epidote and quartz. The metasedimentary rocks are banded iron formations, quartzites and schists with variable amounts of quartz, muscovite, kyanite, andalusite, corundum, garnet, staurolite, chloritoid, chlorite, tourmalines and rutile/leucoxene. The stable association of staurolite and chloritoid enabled to establish the temperature conditions of the regional Archean metamorphic event, which formed the country rocks and the protolith of the agalmatolite, at T $\sim 500-550^{\circ} \mathrm{C}$. The observed replacement of kyanite by andalusite indicates an episode of decreasing pressure to less the 4kbar, possibly during the regional metamorphic event. The agalmatolite was formed at $\mathrm{T} \sim 350-400^{\circ} \mathrm{C}$ at the expenses of peraluminous metassedimentary rocks with variable amounts of kyanite, andalusite, muscovite, and quartz. Pyrophyllite was generated by hydrothermal alteration of these rocks along shear zones of possible Transamazonian age, which acted as sinks for $\mathrm{H}_{2} \mathrm{O}$-rich fluids.

Keywords: agalmatolite, Minas Gerais, pyrophyllite, petrography, petrogenesis.

1 - Departamento Geologia, Escola de Minas, Universidade Federal de Ouro Preto Ouro Preto (MG), Brasil. E-mail: hanna@degeo.ufop.br 2 - Pós-Graduando do Departamento de Geologia, Escola de Minas, Universidade Federal de Ouro Preto, Ouro Preto (MG), Brasil. E-mail: delgado@geologist.com 
INTRODUÇÃO Agalmatolito é uma rocha metamórfica peraluminosa composta por pirofilita e largamente empregada como carga mineral nas indústrias de tinta, cerâmica, borracha e celulose (Luz et al. 2005). Em Minas Gerais, diversas ocorrências e minas de agalmatolito concentram-se num lineamento morfo-estrutural de direção NW-SE, com cerca de $80 \mathrm{~km}$ de extensão e situado a noroeste de Belo Horizonte, abrangendo parte dos municípios de Pará de Minas, Mateus Leme, Onça de Pitangui e Pitangui (Fig. 1). Os depósitos são lenticulares, com centenas de metros de comprimento e espessura variando de 20 a 120m (Luz et al. 2001). Várias dessas ocorrências foram objeto de estudos gerais durante a primeira metade do século XX (Leinz 1938, Moraes 1938). Mineralogia e propriedades físicas desse minério foram descritas por Nogueira \& Barzaghi (1972).

Embora agalmatolito seja, por definição, uma rocha essencialmente constituída de pirofilita, comercialmente aceitam-se tipos litológicos que contenham moscovita, quartzo e, às vezes, cianita e andaluzita, utilizados em blendagens para atender a especificações mercadológicas.

Tendo em vista a grande importância econômica do agalmatolito, este trabalho objetiva contribuir para o conhecimento da mineralogia, das texturas/microestruturas e da gênese dos diversos tipos litológicos industrialmente utilizados como agalmatolito. Considerando a grande semelhança, em termos de propriedades, de pirofilita e moscovita, que são os dois principais filossilicatos constituintes dos litotipos explotados, procurouse investigar como distinguir esses minerais de modo prático, possibilitando a classificação do tipo de minério por métodos de custo relativamente baixo.

ARCABOUÇO GEOLÓGICO As ocorrências de agalmatolito da região estudada ocorrem associadas principalmente a quartzitos, com intercalações de rochas metavulcânicas ácidas a intermediárias atribuídas ao Supergrupo Rio das Velhas (Romano 1989). Segundo Heineck (1997) e Heineck \& Drumond (2004) a região é constituída por terrenos granito-greenstone arqueanos, integrados por rochas da infra-estrutura plutônica do Cráton do São Francisco e pela seqüência metavulcanossedimentar do greenstone belt Rio das Velhas (Fig. 1). Os corpos de agalmatolito encontram-se num contexto de rochas que sofreram intensas alterações hidrotermais e segundo níveis bem definidos. As dimensões dessas zonas de alteração apresentam até vários quilômetros de extensão e espessuras decamétricas. A cartografia geológica mostrou que os corpos de rochas peraluminosas são bastante extensos, mas restritos às principais descontinuidades tectônicas produzidas tanto ao longo do contato entre as rochas plutônicas e as de natureza supracrustal, como dentro da própria pilha metavulcanossedimentar, ocupando, portanto, posições bastante diversas no interior da estratigrafia. Uma tectônica tangencial, compressiva, responsável pelo desenvolvimento dessas estruturas, é atribuída à atuação do Ciclo Transamazônico e exerceu um acentuado controle de natureza tectônica na constituição das estru- turas que favoreceram o fluxo de fluidos hidrotermais. A análise da deformação mostrou que os processos de alteração hidrotermal provavelmente foram síncronos do sistema compressivo que induziu os transportes de massa por cavalgamentos e movimentos transcorrentes no sentido WNW.

MATERIAIS E MÉTODOS A caracterização petrográfica e a interpretação petrogenética de diversos tipos de agalmatolito da região de Pará de Minas-Pitangui, bem como de suas rochas encaixantes fundamentaramse no estudo petrográfico por microscopia de luz transmitida de 50 lâminas delgadas polidas, na difração de raios X e em análises textural e de química mineral obtidas por MEV/EDS.

Foram estudas amostras coletadas na região de Pará de Minas, Pitangui e Azurita (Fig. 1), bem como testemunhos de sondagem provenientes da mina da Lamil Mineração, localizada em Pará de Minas. A tabela 1 traz uma compilação das características macroscópicas e da mineralogia de amostras representativas do minério e das encaixantes estudadas no presente trabalho.

Amostras pulverizadas foram analisadas por difratometria de raios $\mathrm{X}$ no equipamento Rigaku, modelo Geigerflex D/Max - B Series do DEGEO/UFOP, que operou em condições de excitação de $20 \mathrm{~mA}$ e $40 \mathrm{kV}$, com intervalo de exposição de $2-70^{\circ}$ e velocidade do goniômetro de $1,2^{\circ} / \mathrm{min}$., $\lambda=1,541838 \AA$, tubo de $\mathrm{Cu}$. A química mineral foi obtida por meio do Microscópio Eletrônico de Varredura (MEV) do DEMET/UFMG, marca Jeol, modelo JSM 6360LV, com Espectrômetro de Energia Dispersiva de Raios X (EDS), marca Thermo Noran, modelo Quest, com condições analíticas de voltagem de aceleração de $15 \mathrm{kV}$ e tempo de análise pontual de 30s. As imagens de varredura foram obtidas em modo BEI (back-scattered electronic imaging).

\section{PETROGRAFIA E PETROGÊNESE}

Agalmatolito e rochas peraluminosas associadas Litotipos ricos em pirofilita, classificados como agalmatolito s.s., gradam para rochas peraluminosas com teores menores de pirofilita, as quais são explotadas para blendagem com agalmatolito. As amostras de diferentes procedências (Pará de Minas, Azurita e Pitangui) são semelhantes em termos mineralógicos e texturais. Na tabela 1 foram classificadas como agalmatolito amostras com mais de $50 \%$ em volume de pirofilita.

PIROFILITA FELS \pm QUARTZO O minério de maior pureza é composto de massa finíssima de pirofilita (Fig. 2), que constitui a quase totalidade da rocha (amostra AG1, Tab. 1). Em quantidade subordinada ocorrem palhetas maiores de moscovita, minerais opacos, zircão, turmalinas, rutilo/leucoxênio e diásporo. Não apresenta foliação. É um litotipo relativamente raro, encontrado principalmente sob a forma de veios de largura decimétrica. Algumas variedades possuem quartzo (amostras AG2 e AG3) em nódulos lenticulares de até 7 × $3 \mathrm{~mm}$, policristalinos, cujos cristais têm forte deformação ma- 


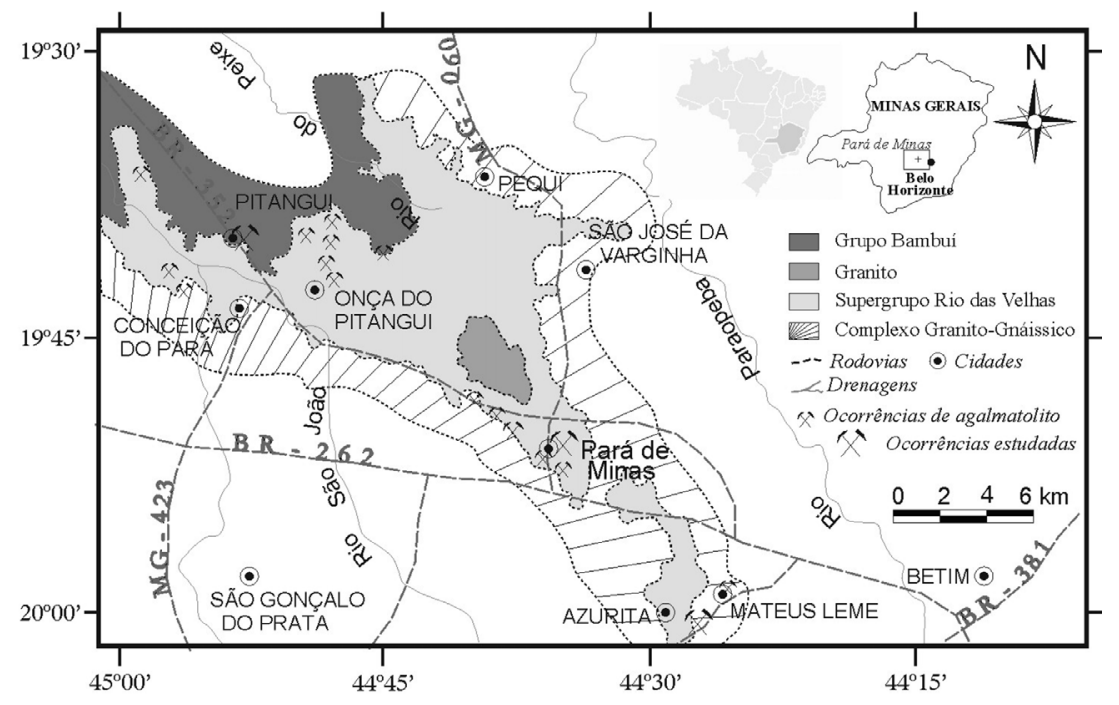

Figura 1 - Mapa geológico e de localização das principais ocorrências de agalmatolito (Lara Filho 1997).

nifestada por extinção ondulante, subgrãos e finíssimos novos grãos produzidos por recristalização dinâmica. $\mathrm{O}$ contato entre os cristais que compõem as lentes é suturado, conforme é típico para os produtos de processos de milonitização. Na borda, os grãos de quartzo sofreram substituição pela pirofilita, o que gerou feições que lembram as cavernas de corrosão marginais de fenocristais de vulcânicas ácidas (Fig. 2). O contorno arredondado (sugestivo de transporte) de alguns nódulos mais preservados da deformação/alteração sugere que originalmente se tratava de grãos detríticos.

DIÁSPORO-PIROFILITA FELS Essa variedade de agalmatolito, exemplificado pela amostra AG4 na tabela 1 , é composta essencialmente por pirofilita e diásporo. A pirofilita constitui palhetas finíssimas, incolores, com tamanho variando de submicroscópico $(<0,01$ $\mathrm{mm}$ ) até $0,03 \mathrm{~mm}$, em arranjo feltroso. É posterior ao diásporo, pois forma filetes que recortam os agregados desse mineral. Diásporo aparece em grãos alongados, tendendo a aciculares curtos, com tamanho médio em torno de $0,02 \mathrm{~mm}$, incolores, com alto relevo e cores de interferência vivas. Nos agregados finos é acastanhado, com aspecto sujo. Moscovita constitui palhetas maiores, com até $0,8 \mathrm{~mm}$ de comprimento. Tem substituição marginal ou paralela à clivagem por pirofilita e diásporo. Pode ser esqueletiforme ou estar deformada, com kink bands. Os minerais acessórios são rutilo, minerais opacos, zircão metamíctico e turmalinas de cor verde.

CIANITA-MOSCOVITA-QUARTZO-PIROFILITA XISTO A FELS \pm ANDALUZITA É uma variedade de agalmatolito cujos principais minerais são pirofilita, cianita, moscovita e quartzo (amostra AG5, Tab. 1). Andaluzita aparece em amostras onde pirofilita ocorre em menor quantidade (amostras RA1, RA2 e RA3, Tab. 1). A pirofilita é de finíssima granulação $(<0,01 \mathrm{~mm})$ e ocorre substituindo os demais minerais. Moscovita aparece em palhetas que podem ou não exibir orien- tação preferencial planar. A variedade sem orientação é produto da alteração de cianita ou andaluzita. É de granulação mais grossa do que a pirofilita, chegando a $2 \mathrm{~mm}$ de comprimento. Quartzo constitui agregados policristalinos de até $3 \mathrm{~mm}$ de comprimento, alongados segundo a foliação e de contorno irregular devido à substituição marginal por pirofilita. Os contatos entre os cristais constituintes dos agregados podem ser do tipo suturado, típicos de origem por recristalização dinâmica em processos de milonitização. Cianita é tabular, de porte centimétrico, apresenta forte deformação manifestada na forma de fraturas, extinção ondulante, kink bands e lamelas de deformação. Nas fraturas há alteração em filossilicatos, mais comumente do tipo lamelar maior, que é a moscovita, mas também em pirofilita finíssima (Fig.3). Pode apresentar substituição parcial ou total por andaluzita. Andaluzita aparece em amostras com teor menor de pirofilita. Os cristais prismáticos chegam a vários centímetros de comprimento, com seções basais com cerca de $2 \mathrm{~cm}$ de lado. Aparece fraturada, com extinção ondulante e alteração em pirofilita e, às vezes, diásporo (Fig. 3). Essa alteração pode ser quase total, às vezes sobreviveram somente "ilhas" de andaluzita com a mesma orientação óptica e que, portanto, faziam parte de um único cristal, imersas na massa de pirofilita. Quando andaluzita tem inclusões de quartzo, forma-se uma auréola da pirofilita no contato entre os dois, o que constitui uma evidência da reação retrometamórfica (1):

andaluzita + quartzo + fluido aquoso $=$ pirofilita

Notável, em várias amostras, é a substituição da cianita por andaluzita, às vezes apenas na borda, outras vezes mais pronunciada (Fig. 4). Quando a substituição é completa, a andaluzita aparece como pseudomorfose com o hábito tabular da cianita. Minerais acessórios são turmalinas, minerais opacos, rutilo, zircão e, às vezes, cloritóide. O rutilo constitui grãos semi-opacos, que 
Tabela 1 - Características macroscópicas, mineralogia e composição modal estimada (em \% volumétrica) de amostras representativas de agalmatolito e suas encaixantes.

\begin{tabular}{|c|c|c|c|}
\hline Amostra & Descrição macroscópica & Mineralogia & Moda (\% em vol.) \\
\hline \multicolumn{4}{|c|}{ Agalmatolito e rochas peraluminosas associadas * } \\
\hline $\begin{array}{l}\text { AG1 - Agalmatolito } \\
\text { (pirofilita fels) }\end{array}$ & $\begin{array}{l}\text { Cor verde-claro, maciça, microcristalina. } \\
\text { Na borda da amostra há foliação }\end{array}$ & $\begin{array}{l}\text { Pirofilita, moscovita, minerais } \\
\text { opacos, zircão, turmalinas, rutilo/ } \\
\text { leucoxênio e diásporo }\end{array}$ & Pirofilita 100 Resto $<1$ \\
\hline $\begin{array}{l}\text { AG2 - Agalmatolito } \\
\text { (quartzo-pirofilita fels) }\end{array}$ & $\begin{array}{l}\text { Cor cinza-esverdeado, maciça, } \\
\text { granulação muito fina, com lentes } \\
\text { milimétricas, de brilho gorduroso, } \\
\text { compostas por quartzo }\end{array}$ & $\begin{array}{l}\text { Pirofilita, quartzo, moscovita, } \\
\text { rutilo, minerais opacos, zircão, } \\
\text { turmalinas }\end{array}$ & $\begin{array}{lr}\text { Pirofilita } 72 & \text { Quartzo } 25 \\
\text { Moscovita } 3 & \text { Resto }<1\end{array}$ \\
\hline $\begin{array}{l}\text { AG3 - Agalmatolito } \\
\text { (quartzo-pirofilita fels) }\end{array}$ & $\begin{array}{l}\text { Cor verde-claro, maciça, granulação } \\
\text { finíssima e esparsas lentes sub- } \\
\text { milimétricas de quartzo }\end{array}$ & $\begin{array}{l}\text { Pirofilita, quartzo, moscovita, } \\
\text { zircão, rutilo, leucoxênio, } \\
\text { minerais opacos, turmalinas }\end{array}$ & $\begin{array}{lr}\text { Pirofilita } 65 & \text { Quartzo } 30 \\
\text { Moscovita } 5 & \text { Resto }<1\end{array}$ \\
\hline $\begin{array}{l}\text { RA1 - Agalmatolito } \\
\text { (diásporo-pirofilita fels) }\end{array}$ & $\begin{array}{l}\text { Cor cinza-claro com leve tonalidade } \\
\text { esverdeada, com cristais milimétricos } \\
\text { ou pequenos veios de turmalinas }\end{array}$ & $\begin{array}{l}\text { Pirofilita, diásporo, moscovita, } \\
\text { zircão, rutilo, minerais opacos, } \\
\text { leucoxênio, turmalinas }\end{array}$ & $\begin{array}{l}\text { Pirofilita } 50 \text { Diásporo } 45 \\
\text { Moscovita } 5\end{array}$ \\
\hline $\begin{array}{l}\text { RA2 - Agalmatolito } \\
\text { (cianita-moscovita- } \\
\text { quartzo-pirofilita xisto) }\end{array}$ & Cor creme, foliada, brilho sedoso & $\begin{array}{l}\text { Pirofilita, quartzo, moscovita, } \\
\text { cianita, rutilo, zircão }\end{array}$ & $\begin{array}{lr}\text { Pirofilita } 50 & \text { Quartzo } 25 \\
\text { Moscovita } 15 & \text { Cianita } 10 \\
\text { Resto }<1 & \\
\end{array}$ \\
\hline RA3 - Moscovita xisto & $\begin{array}{l}\text { Cor creme-acinzentado, granulação } \\
\text { muito fina, foliada e crenulada }\end{array}$ & Moscovita, rutilo, zircão & Moscovita 100 Resto $<1$ \\
\hline RA 4 - Moscovita xisto & $\begin{array}{l}\text { Cor verde-claro a creme, estrutura } \\
\text { foliada }\end{array}$ & $\begin{array}{l}\text { Moscovita, minerais opacos, } \\
\text { zircão }\end{array}$ & $\begin{array}{l}\text { Moscovita } 97 \quad \text { Opacos } 3 \\
\text { Zircão }<1\end{array}$ \\
\hline $\begin{array}{l}\text { RA } \quad 5-\text { Quartzo- } \\
\text { moscovita xisto }\end{array}$ & $\begin{array}{l}\text { Cor rosa-arroxeado com porções de cor } \\
\text { clara, creme; foliação. }\end{array}$ & $\begin{array}{l}\text { Quartzo, moscovita, zircão, } \\
\text { minerais opacos turmalinas, } \\
\text { rutilo/leucoxênio, }\end{array}$ & $\begin{array}{l}\text { Moscovita } 75 \text { Quartzo } 25 \\
\text { Resto }<1\end{array}$ \\
\hline $\begin{array}{l}\text { RA6 - } \\
\text { Quartzo-moscovita xisto }\end{array}$ & $\begin{array}{l}\text { Cor cinza-claro, com grãos lenticulares } \\
\text { de quartzo de tamanho milimétrico } \\
\text { envoltos pela mica. }\end{array}$ & $\begin{array}{l}\text { Moscovita, quartzo, rutilo, } \\
\text { zircão }\end{array}$ & $\begin{array}{ll}\text { Moscovita } 60 & \text { Quartzo } 40 \\
\text { Resto }<1 & \end{array}$ \\
\hline $\begin{array}{l}\text { RA6 - Quartzo-andal.- } \\
\text { mosc.-pirof.-cianita fels }\end{array}$ & $\begin{array}{l}\text { Cor cinza-claro, maciça, textura } \\
\text { granular }\end{array}$ & $\begin{array}{l}\text { Cianita, pirofilita, moscovita, } \\
\text { andaluzita, quartzo, diásporo, } \\
\text { coríndon, rutilo, zircão, opaco }\end{array}$ & $\begin{array}{lc}\text { Cianita } 30 & \text { Pirofilita } 20 \\
\text { Moscovita 20 } & \text { Andaluzita } \\
15 \text { Quartzo 10 } & \text { Resto 5 }\end{array}$ \\
\hline $\begin{array}{l}\text { RA 7- Cianita-andaluzita } \\
\text { fels }\end{array}$ & $\begin{array}{l}\text { Maciça, com porções rosadas salpicadas } \\
\text { por turmalinas negras e porções } \\
\text { esverdeadas de brilho sedoso }\end{array}$ & $\begin{array}{l}\text { Andaluzita, moscovita, cianita, } \\
\text { quartzo, turmalinas, diásporo, } \\
\text { pirofilita, cloritóide, rutilo, } \\
\text { zircão }\end{array}$ & $\begin{array}{l}\text { Andaluzita } 50 \text { Moscovita } \\
20 \text { Quartzo } 10 \text { Cianita } 10 \\
\text { Pirofilita } 5 \text { Turmalinas } 5\end{array}$ \\
\hline $\begin{array}{l}\text { RA 8- Pirofilita-mosc.- } \\
\text { cianita-andaluzita fels }\end{array}$ & $\begin{array}{l}\text { Amostra esférica com película micácea, } \\
\text { cor cinza-claro, com cristais centímetros } \\
(8 \times 3 \mathrm{~cm}) \text { de andaluzita rosada e tabulares } \\
\text { de cianita }\end{array}$ & $\begin{array}{l}\text { Cianita, andaluzita, pirofilita, } \\
\text { moscovita, quartzo, coríndon, } \\
\text { rutilo, zircão, diásporo }\end{array}$ & $\begin{array}{ll}\text { Andaluzita } 45 & \text { Cianita } 40 \\
\text { Moscovita } 5 & \text { Pirofilita } 5 \\
\text { Resto 5 } & \end{array}$ \\
\hline
\end{tabular}

Rochas encaixantes do agalmatolito**

\begin{tabular}{|c|c|c|c|}
\hline $\begin{array}{l}\text { ENC1 - } \\
\text { Metaígnea } \\
\text { (meta-latito?) }\end{array}$ & $\begin{array}{l}\text { Cinza-esverdeado escuro, foliação } \\
\text { incipiente, nódulos brancos de } \\
\text { carbonato }\end{array}$ & $\begin{array}{l}\text { Moscovita, feldspato alcalino, } \\
\text { epidoto, pirofilita, quartzo, } \\
\text { clorita, zircão, opacos, carbonato }\end{array}$ & $\begin{array}{l}\text { Moscovita } 40 \quad \text { Feldspato } \\
\text { alcalino } 30 \quad \text { Epidoto } 20 \\
\text { Quartzo } 7 \text { Resto } 3\end{array}$ \\
\hline $\begin{array}{l}\text { ENC2 - } \\
\text { Metaígnea } \\
\text { (meta-latito?) }\end{array}$ & $\begin{array}{l}\text { Rocha esverdeada, lentes de feldspato } \\
\text { de cor rosa e tamanho de } 1 \text { a } 2 \mathrm{~cm} \text {, raro } \\
\text { até } 10 \mathrm{~cm}\end{array}$ & $\begin{array}{l}\text { Feldspato alcalino (microclina), } \\
\text { moscovita, quartzo, epidoto, } \\
\text { clorita, apatita, zircão, mineral } \\
\text { semi-opaco }\end{array}$ & $\begin{array}{l}\text { Feldspato alcalino } 45 \text { Mica } \\
\text { branca } 45 \text { Quartzo } 5 \text { Resto } \\
5\end{array}$ \\
\hline $\begin{array}{l}\text { ENC3 - Metaígnea } \\
\text { ( m e t a r i o } 1 \text { i t o / } \\
\text { metadacito?) }\end{array}$ & $\begin{array}{l}\text { Cor cinza-esverdeado, nódulos/ } \\
\text { lentes de tamanho centimétrico e cor } \\
\text { esbranquiçada }\end{array}$ & $\begin{array}{l}\text { Quartzo, plagioclásio, moscovita, } \\
\text { clorita, microclina, clinozoisita, } \\
\text { zircão, apatita }\end{array}$ & $\begin{array}{l}\text { Quartzo } 30 \text { Plagioclásio } 25 \\
\text { Moscovita } 20 \text { Microclina } \\
15 \quad \text { Clorita } 10\end{array}$ \\
\hline $\begin{array}{l}\text { ENC4 - Clorita- } \\
\text { moscovita xisto }\end{array}$ & Rocha foliada, cor escura & $\begin{array}{l}\begin{array}{l}\text { Moscovita, } \\
\text { carbonato, } \\
\text { apatita }\end{array} \\
\text { titanita, }\end{array}$ & $\begin{array}{l}\text { Moscovita } 75 \quad \text { Clorita } 25 \\
\text { Resto }<1\end{array}$ \\
\hline $\begin{array}{l}\text { ENC5 - Granada- } \\
\text { estaurolita. xisto }\end{array}$ & $\begin{array}{l}\text { Cor cinza-esverdeado, granulação fina e } \\
\text { homogêna e foliação incipiente }\end{array}$ & $\begin{array}{l}\text { Quartzo, moscovita, biotita, } \\
\text { clorita, granada, estaurolita, } \\
\text { turmalinas, apatita, zircão }\end{array}$ & $\begin{array}{lr}\text { Quartzo } 45 & \text { Moscovita } \\
25 \text { Clorita10 } & \text { Biotita 10 } \\
\text { Granada } 5 \quad \text { Estaurolita 5 }\end{array}$ \\
\hline $\begin{array}{l}\text { ENC6 - Granada- } \\
\text { estaurolita-moscovita } \\
\text { xisto }\end{array}$ & $\begin{array}{l}\text { Cor esverdeada, porfiroblastos de } \\
\text { granada centimétricos envolvidos por } \\
\text { película de clorita }\end{array}$ & $\begin{array}{l}\text { Moscovita, estaurolita, granada, } \\
\text { quartzo, cloritóide, clorita, } \\
\text { opacos, zircão, apatita }\end{array}$ & $\begin{array}{l}\text { Moscovita } 55 \text { Estaurolita } 30 \\
\text { Granada } 10 \text { Resto } 5\end{array}$ \\
\hline $\begin{array}{l}\text { ENC7 - } \\
\text { Cloritóide-granada fels }\end{array}$ & $\begin{array}{l}\text { Rocha maciça, esverdeada, com granada } \\
\text { rosada e cloritóide tabular preto- } \\
\text { esverdeado, de tamanho milimétrico }\end{array}$ & $\begin{array}{l}\text { Granada, moscovita, cloritóide, } \\
\text { clorita, quartzo, turmalinas, } \\
\text { estaurolita, rutilo, zircão, opacos }\end{array}$ & $\begin{array}{lr}\text { Granada } 70 & \text { Moscovita } \\
10 \text { Clorita } 8 & \text { Cloritóide } 7 \\
\text { Quartzo 5 } & \\
\end{array}$ \\
\hline
\end{tabular}

* Rochas de Pará de Minas, Pitangui e Azurita ** Rochas de Pará de Minas 
podem alinhar-se constituindo cordões ou concentrarse localmente em pequenos nódulos. É relativamente abundante e pode chegar a $1-2 \%$ em volume em algumas amostras. $\mathrm{O}$ zircão apresenta-se euédrico, em prismas acastanhados e em avançado estágio de isotropização, portando trata-se de zircão metamíctico. As turmalinas podem constituir agregados radiais em veios de quartzo que preenchem fraturas em cianita ou andaluzita. Em algumas amostras foi ainda identificado coríndon em poucos grãos relícticos dentro da andaluzita, caracterizados pelo alto relevo e caráter óptico uniaxial negativo.

As texturas de substituição de cianita e andaluzita por pirofilita (Fig. 3) indicam a seguinte reação retrometamórfica decorrente de declínio de temperatura e percolação de fluido aquoso (1):

Cianita/andaluzita + quartzo + fluido aquoso $=$ pirofilita (1) $\mathrm{Al}_{2} \mathrm{SiO}_{5}+3 \mathrm{SiO}_{2}+\mathrm{H}_{2} \mathrm{O}=\mathrm{Al}_{2} \mathrm{Si}_{4} \mathrm{O}_{10}(\mathrm{OH})_{2}$ $\left(\mathrm{T}=400^{\circ} \mathrm{C}\right.$ para $\mathrm{P}=3,5 \mathrm{kbar}$, Haas \& Holdaway 1973$)$

Para formar o diásporo, a seguinte reação decorre da infiltração de fluido aquoso no retrometamorfismo (2):

Cianita/andaluzita + fluido aquoso $=$ diásporo + quartzo

$\mathrm{Al}_{2} \mathrm{SiO}_{5}+\mathrm{H}_{2} \mathrm{O}=2 \mathrm{AlO}(\mathrm{OH})+\mathrm{SiO}_{2}$

A substituição de andaluzita ou cianita por diásporo e pirofilita, conforme se observa na figura 3 , é decorrente da seguinte reação (3):

Andaluzita/cianita + fluido aquoso $=$ pirofilita + diásporo (soma das reações $1+2$ )

$4 \mathrm{Al}_{2} \mathrm{SiO}_{5}+4 \mathrm{H}_{2} \mathrm{O}=\mathrm{Al}_{2} \mathrm{Si}_{4} \mathrm{O}_{10}(\mathrm{OH})_{2}+6 \mathrm{AlO}(\mathrm{OH})$

$\left(\mathrm{T}=350^{\circ} \mathrm{C}\right.$ para $\mathrm{P}=3,5 \mathrm{kbar}$, Haas \& Holdaway 1973$)$.

Na reação (1) sílica é liberada, a qual é consumida na (2). Na figura 3 observa-se que o diásporo encontra-se na borda do veio de alteração, em contato direto com andaluzita, enquanto que a pirofilita preenche a porção central. Possivelmente, isso pode ser explicado pela maior percolação de fluidos na porção central da fratura, fluidos esses que provavelmente carreavam a sílica liberada da reação de formação do diásporo ou advinda de outros sítios, possibilitando a formação da pirofilita. Observa-se em muitas rochas que os grãos de quartzo apresentam bordas corroídas em meio à massa de pirofilita (Fig. 2), um claro indício de dissolução e provável participação nas reações de formação de pirofilita.

Nas amostras com coríndon, uma reação retrometamórfica provável envolvendo esse mineral foi (4):

Coríndon + fluido aquoso $=$ diásporo

$\mathrm{Al}_{2} \mathrm{O}_{3}+\mathrm{H}_{2} \mathrm{O}=2 \mathrm{AlO}(\mathrm{OH})$

$\left(\mathrm{T}=410^{\circ} \mathrm{C}\right.$ para $\mathrm{P}=3,5 \mathrm{kbar}$, Haas 1972$)$

A observada substituição de moscovita por pirofilita decorre de reação do tipo (5):
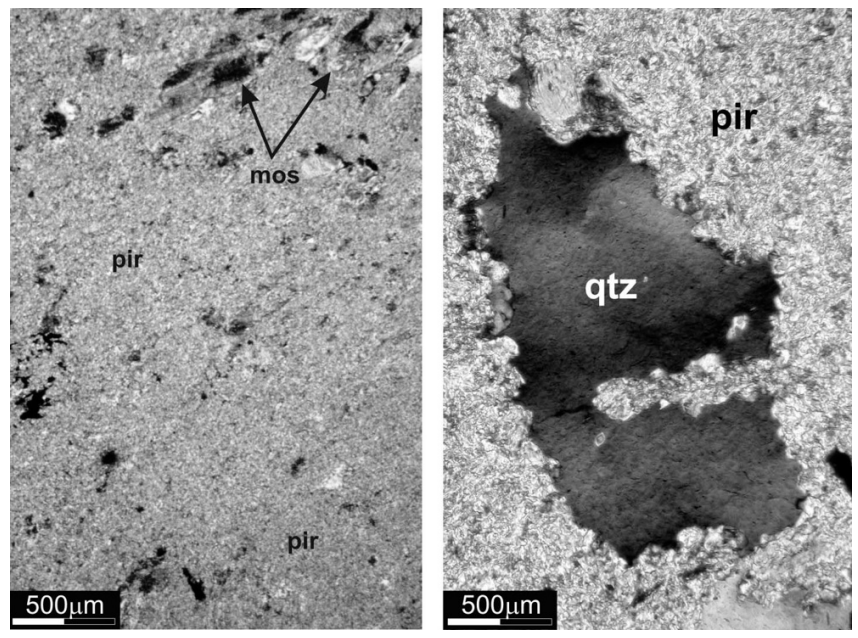

Figura 2 - À esquerda: fotomicrografia de pirofilita fels da mina de Pará de Minas, mostrando agregado finíssimo de pirofilita não-orientada (pir) e palhetas maiores de moscovita (mos); LPX. À direita: fotomicrografia de agalmatolito mostrando quartzo (qtz) com contorno irregular por substituição marginal por pirofilita; $L P X$.
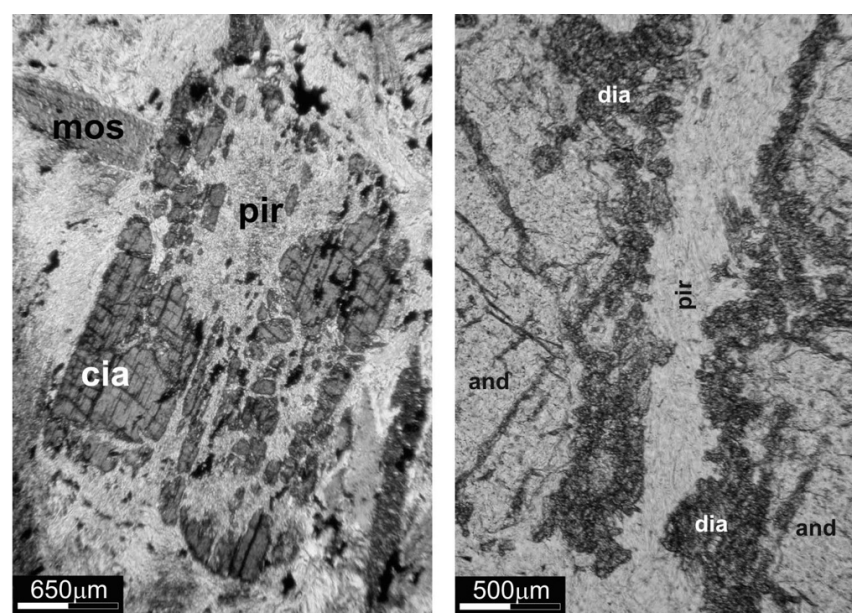

Figura 3 - À esquerda: fotomicrografia de cianita parcialmente substituida por pirofilita, cianita xisto de Onça do Pitangui; LPX. À direita: fotomicrografia de andaluzita (and) com alteração em diásporo (dia) e pirofilita (pir), cianita-andaluzita xisto de Pará de Minas; $L P P$.

Moscovita + quartzo $+\mathrm{H}^{+}=$pirofilita

$\mathrm{KAl}_{2} \mathrm{Si}_{3} \mathrm{O}_{10}(\mathrm{OH})_{2}+3 \mathrm{SiO}_{2}+\mathrm{H}^{+}=1,5 \mathrm{Al}_{2} \mathrm{Si}_{4} \mathrm{O}_{10}(\mathrm{OH})_{2}+\mathrm{K}^{+}$

MOSCOVITA XISTO É uma rocha peraluminosa explotada para blendagem com agalmatolito. Pode ser essencialmente composta por moscovita (amostras RA4 e RA5, Tab. 1) ou conter também quartzo (RA e RA7). Há dois tipos granulométricos de moscovita. $\mathrm{O}$ tipo fino pode constituir curiosos agregados, com arranjos de fibras/lamelas dispostas de modo sub-radial ou paralelo. O tamanho dos agregados é diminuto, na faixa de 0,1 $\mathrm{mm}$, o das palhetas individuais é muito menor. Nos es- 
paços entre os agregados ocorre um feltro de palhetas finíssimas e decussadas. A identificação desse tipo fino como moscovita baseou-se na difração de raios $\mathrm{X}$. O tipo de granulação maior constitui palhetas relativamente grandes (até $0,8 \mathrm{~mm}$ ) com orientação preferencial planar, responsável pela foliação da rocha que pode estar crenulada. Tem forte extinção ondulante, kink bands e desagregação no tipo fino, o que leva os restos não substituídos a adquirir hábito esqueletiforme. O quartzo ocorre como porfiroclastos arredondados ou lenticulares, com até $1 \mathrm{~cm}$ por $3,5 \mathrm{~mm}$. Os cristais componentes das lentes chegam a $2 \mathrm{~mm}$ de tamanho e possuem acentuada deformação interna na forma de extinção ondulante. $\mathrm{Na}$ borda houve recristalização em finos novos grãos e, às vezes, os porfiroclastos são ladeados por caudas de recristalização dinâmica (Fig. 4). O aspecto arredondado dos porfiroclastos sugere que se trata de grãos de origem sedimentar detrítica recristalizados dinamicamente. Os minerais acessórios são, rutilo/leucoxênio, zircão com acentuada isotropização e minerais opacos.

Rochas encaixantes As rochas encaixantes do agalmatolito são quartzitos, metavulcânicas, xistos e formação ferrífera, além das rochas peraluminosas, descritas junto com o agalmatolito. Abaixo segue a descrição das metavulcânicas e xistos. Quartzitos e formação ferrífera não foram amostrados devido à mineralogia relativamente simples: quartzitos são essencialmente compostos por quartzo associado a menor quantidade de mica branca; a formação ferrífera possui quartzo e óxidos de ferro.

META-LATITO/META-RIOLITO As rochas metaígneas encontradas na região de Pará de Minas têm cor esverdeada, foliação incipiente e portam fenocristais, que chegam a atingir $10 \mathrm{~cm}$, de feldspato alcalino rosado. Em lâmina delgada verifica-se que a maior parte do feldspato alcalino constitui nódulos policristalinos, lenticulares, com variável grau de recristalização dinâmica em novos grãos, às vezes exibindo microestrutura núcleo-manto. Alteração em mica branca é de intensidade variável. Grande parte dos cristais tem maclas em grade, tratando-se, portanto, de microclina. Há também grãos de ortoclásio, sem esse tipo de macla, logo o álcali-feldspato possui variável grau de triclinicidade. Os remanescentes da recristalização (relictos) ainda preservam, às vezes, o hábito magmático tabular e macla de Carlsbad (Fig. 5). Plagioclásio, turvo por alteração, só está preservado em raras amostras. A matriz, de natureza metamórfica, é composta por epidoto, mica branca, clorita, carbonato e quartzo. Epidoto ocorre grãos idioblásticos, às vezes esqueletiformes, pleocróicos em matizes verde-amarelados e zonados. Raramente pode ser rosado, cor típica do epidoto manganesífero piemontita. Os grãos pequenos são amarronzados e com aspecto sujo, provavelmente trata-se de allanita isotropizada. Mica branca aparece em palhetas de tamanhos variáveis, ora orientadas preferencialmente e ora em arranjos sub-radiais. Há também um tipo de filossilicato constituindo agregados muitíssimo finos, que pode ser
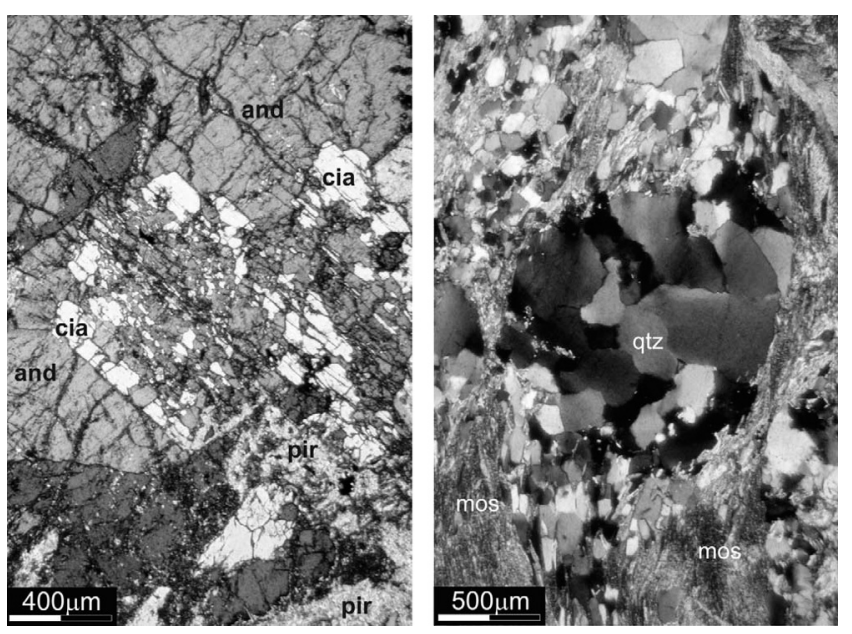

Figura 4 - À esquerda: fotomicrografia de andaluzita (AND) com relictos de cianita (CIA) e alteração em pirofilita (PIR), cianita-andaluzita xisto da mina de Pará de Minas; LPX. À direita: clasto arredondado de quartzo (qtz) recristalizado dinamicamente, de provável origem sedimentar detrítica e ladeado por sombras de pressão, quartzo-moscovita xisto de Pará de Minas; $L P X$.
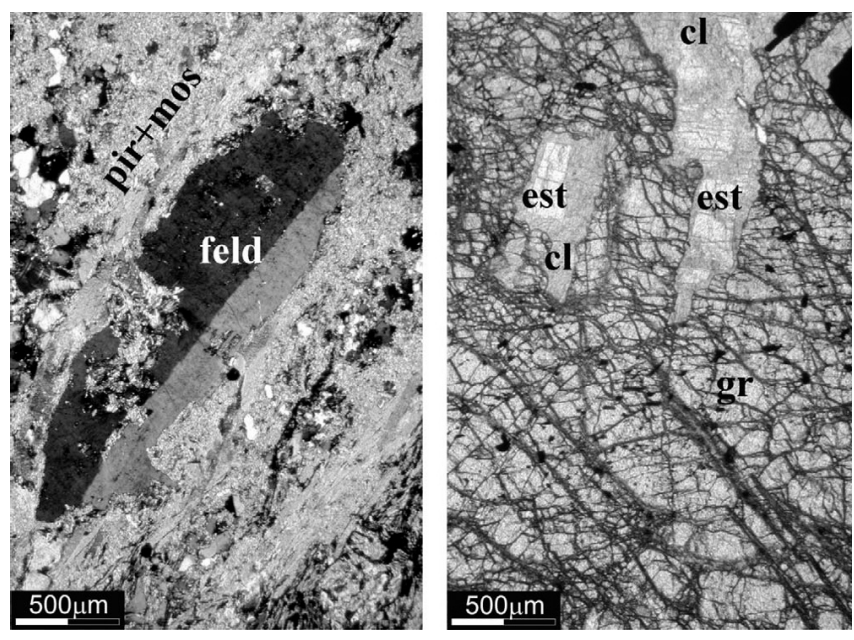

Figura 5 - Fotomicrografias de encaixantes do agalmatolito da mina de Pará de Minas. À esquerda: metavulcânica com fenocristal relíctico de feldspato alcalino (feld) e matriz com pirofilita (pir) e moscovita (mos); LPX. À direita: porfiroblasto de granada (gr) com inclusão de estaurolita (est) envolvida por cloritóide (cl), granada-estaurolita xisto; LPP.

pirofilita. Quartzo é escasso na maioria das amostras e ocorre principalmente em áreas de sombra de pressão junto às lentes de feldspato alcalino. Clorita é verde e tem cor de interferência muito baixa, castanho-arroxeada, característica de cloritas mais ricas em Fe do que em Mg. Minerais acessórios são: zircão metamíctico, apatita e minerais opacos.

A classificação dessas amostras como metavulcânicas deve-se à presença dos fenocristais relícticos de 
feldspato alcalino (Fig. 5). Como o grau de alteração metamórfica é avançado, a maior parte do plagioclásio não sobreviveu, tendo-se transformado em, provavelmente, epidoto e mica branca. Como o teor de quartzo é pequeno na maioria das amostras (em torno de $5 \% \mathrm{em}$ volume), a rocha original poderia corresponder a um latito ou, no caso de amostras com maior teor de quartzo, a riolito/riodacito.

CLORITÓIDE-GRANADA-ESTAUROLITA-MOSCOVITA XISTO Essa rocha, cujo protólito é um metapelito rico em $\mathrm{Fe}$, é composta predominantemente por moscovita e porta porfiroblastos de estaurolita e granada (Fig. 5), além de quartzo, cloritóide, biotita, clorita, minerais opacos, zircão, turmalinas, rutilo e apatita em quantidades subordinadas. Moscovita constitui lamelas com orientação preferencial planar e forma a matriz para os porfiroblastos. Biotita só aparece em algumas amostras, tem forte deformação e alteração em clorita. Estaurolita ocorre em prismas decussados, deformados (quebrados ou tortos) e com até $3 \mathrm{~mm}$ de comprimento, relativamente pequenos quando comparados com os porfiroblastos de granada. Cloritóide aparece em cristais tabulares com abundantes maclas polissintéticas. Pode ter fraca alteração em clorita. Granada forma porfiroblastos poiquiloblásticos euédricos, de tamanho centimétrico, com abundantes inclusões de cloritóide, estaurolita, turmalinas, moscovita, quartzo, rutilo, zircão e minerais opacos. Enquanto a estaurolita não inclusa em granada constitui uma paragênese aparentemente estável com cloritóide, na amostra onde aparece dentro da granada ela apresenta evidência de transformação marginal em cloritóide (Fig. 5). A transformação retrometamórfica de estaurolita em cloritóide pode decorrer da reação (6):

Estaurolita + almandina + fluido aquoso= cloritóide + quart-

$2 \mathrm{Fe}_{4} \mathrm{Al}_{18} \mathrm{Si}_{7,5} \mathrm{O}_{44}(\mathrm{OH})_{4}+5 \mathrm{Fe}_{3} \mathrm{Al}_{2} \mathrm{Si}_{3} \mathrm{O}_{12}+19 \mathrm{H}_{2} \mathrm{O}=$ $23 \mathrm{FeAl}_{2} \mathrm{SiO}_{6}(\mathrm{OH})_{2}+7 \mathrm{SiO}_{2}$

$\left(\mathrm{T} \sim 550^{\circ} \mathrm{C}\right.$, para $\mathrm{P}=5 \mathrm{kbar}$, Bucher \& Frey 1994).

A granada pode apresentar alteração em filossilicato fino e/ou clorita esverdeada. Clorita tem cor de interferência acinzentada e sinal do alongamento positivo, característico para a ferro-clorita. Aparece como alteração da granada em fraturas ou intercrescida com a mica branca na matriz da rocha. Quartzo é escasso e pode estar preenchendo fraturas na granada. Minerais acessórios são: zircão, quase totalmente isotropizado (metamíctico), rutilo/leucoxênio, mineral do grupo das turmalinas (dicroísmo de pardo escuro a amarelado) e mineral opaco.

Distinção entre pirofilita e moscovita A moscovita foi encontrada inclusive nas rochas com elevados teores de pirofilita. Como a distinção entre pirofilita e moscovita em lâmina delgada é dificultada pela grande semelhança de suas propriedades ópticas, foram realizadas análises de difração de raios $\mathrm{X}$ de rocha total para verificar a presença desses minerais. Nos difratogramas é claramente possível distinguir pirofilita de moscovita nas rochas em que os dois minerais aparecem em teores apreciáveis. Verifica-se, ainda, que a comparação da altura dos picos relativos ao plano basal $\{001\}$, permite avaliar, semi-quantitativamente, a proporção entre os dois minerais. Por exemplo, na figura 6, que mostra um difratograma de material com $75 \%$ de moscovita e $25 \%$ de pirofilita, o pico referente à $\{001\}$ em $2 \theta$ próximo de $10^{\circ}$ da moscovita é muito mais alto do que o da pirofilita, o que indica a proporção maior do primeiro mineral em relação ao segundo. No entanto, quando os teores de pirofilita e moscovita são baixos ou quando a rocha contém diversos outros minerais, a caracterização da proporção dos citados minerais por difração fica prejudicada.

Ainda objetivando distinguir pirofilita de moscovita foram efetuadas análises de MEV/EDS para constatar se os dois minerais podem ser distinguidos pelo seu hábito possibilitando, em caso afirmativo, a quantificação volumétrica por meio da análise por microscopia óptica em lâmina delgada. Os resultados analíticos de moscovita, pirofilita e diásporo constam da tabela 2 , que, aliados às imagens de elétrons retroespa-

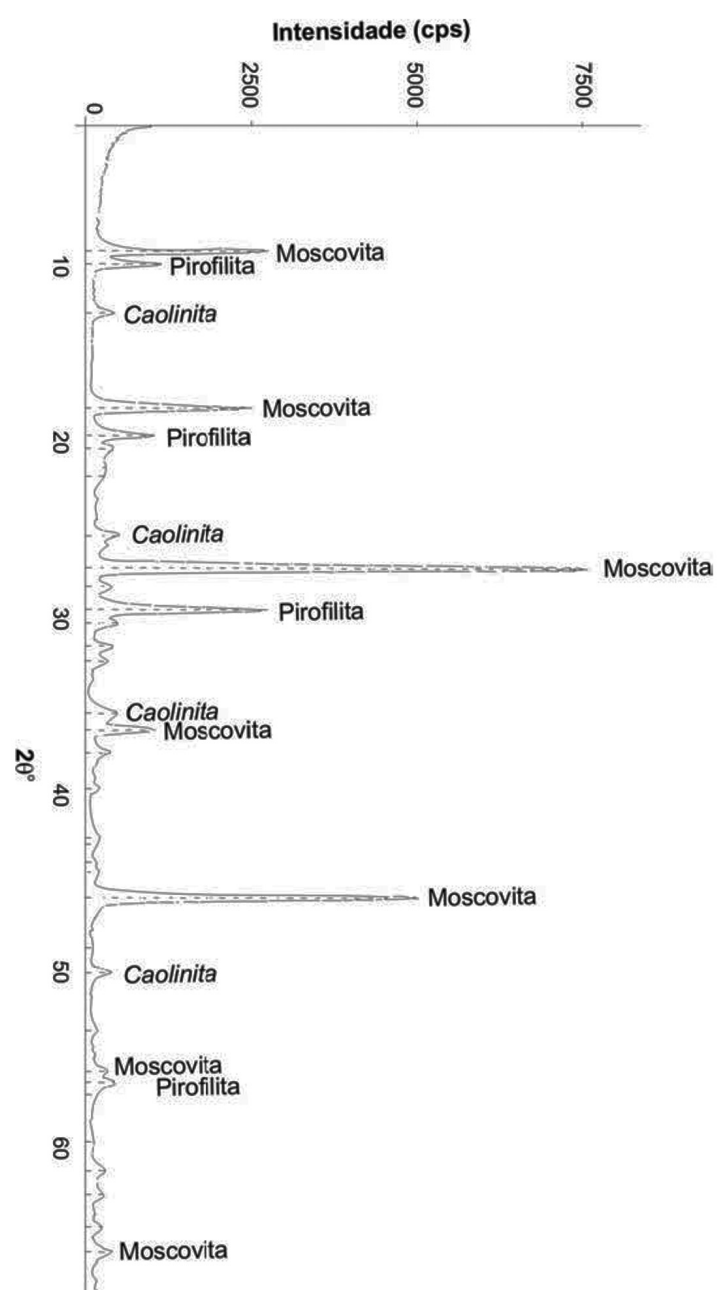

Figura 6 - Difratograma de raios X de agalmatolito com cerca de $75 \%$ de moscovita, $25 \%$ de pirofilita e pequena quantidade de caulinita. 
Tabela 2 - Composição química semiquantitativa (\% peso, normalizada para 100 em base anidra), de filossilicatos e diásporo do agalmatolito e encaixantes obtida por MEV/EDS.

\begin{tabular}{c|c|c|c|c|c|c|c}
\hline & Mineral & $\mathrm{SiO}_{2}$ & $\mathrm{Al}_{2} \mathrm{O}_{3}$ & $\mathrm{Fe}_{2} \mathrm{O}_{3}{ }^{*}$ & $\mathrm{~K}_{2} \mathrm{O}$ & $\mathrm{Na}_{2} \mathrm{O}$ & Total \\
\hline \multirow{3}{*}{1} & Pir & 69,0 & 30,8 & 0,0 & 0,2 & 0,0 & 100 \\
\cline { 2 - 7 } & Mos & 50,4 & 39,1 & 0,0 & 9,0 & 1,5 & 100 \\
\cline { 2 - 8 } & Dia & 2,8 & 97,0 & 0,0 & 0,2 & 0,0 & 100 \\
\hline \multirow{2}{*}{2} & Pir & 68,9 & 30,7 & 0,0 & 0,4 & 0,0 & 100 \\
\cline { 2 - 8 } & Mos & 49,2 & 40,2 & 0,0 & 10,6 & 0,0 & 100 \\
\hline 3 & Pir & 70,5 & 29,5 & 0,0 & 0,0 & 0,0 & 100 \\
\hline 4 & Mos** & 53,3 & 30,7 & 4,9 & 11,1 & 0,0 & 100 \\
\hline
\end{tabular}

*Fe(total) como $\mathrm{Fe}_{2} \mathrm{O}_{3}$; **Filossilicato fino com forte orientação; 1-Pirofilita fels, 2-Moscovita-quartzopirofilita xisto, 3-Cianita-andaluzita fels, 4-Metavulcânica; Pir=pirofilita, Mos=moscovita, Dia=diásporo.

lhados (Fig. 7), permitem a distinção desses três minerais. Verifica-se, assim, que as palhetas de porte maior são sempre moscovitas, enquanto que as finas podem ser pirofilita ou moscovita. No entanto, sempre que o filossilicato fino apresenta orientação preferencial planar, trata-se de moscovita, enquanto que a pirofilita invariavelmente constitui agregados decussados.

Como essas feições texturais também são visíveis na microscopia óptica convencional, habilita-se, assim, o seu emprego como importante ferramenta para a caracterização dos diversos tipos de agalmatolito, com a vantagem de se conseguir uma boa estimativa da proporção de pirofilita e moscovita, aliada aos menores custos das análises empregadas.
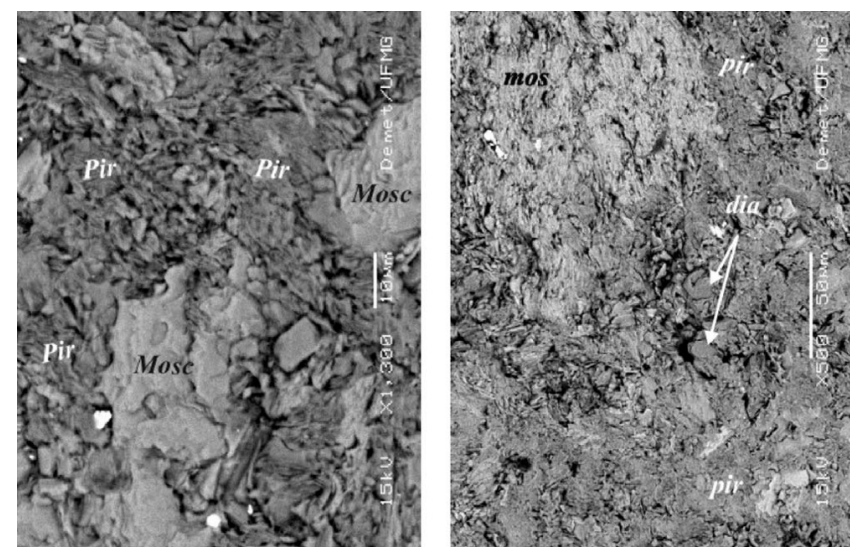

Figura 7 - Imagens de MEV de agalmatolito mostrando as diferenças texturais entre moscovita (mosc), pirofilita (pir) e diásporo (dia).

\section{DISCUSSÃO E CONCLUSÕES}

Metamorfismo regional Cloritóide e estaurolita, encontrados nas encaixantes do agalmatolito, são bons indicadores de grau metamórfico, sendo o primeiro típico de fácies xisto verde e a segunda, de fácies anfibolito, embora possam ocorrer juntos na fácies anfibolito baixo, entre 500 e $550^{\circ} \mathrm{C}$. Em algumas amostras os dois minerais parecem constituir uma paragênese estável, mas em outras, as relações texturais apontam o contrário, pois estaurolita constitui relictos envolvidos pelo cloritóide (Fig. 5). Portanto, reações retrometamórficas no início do processo de resfriamento, mas ainda em condições da fácies anfibolito, levaram à parcial transformação de estaurolita em cloritóide, que, de acordo com a reação (6), ocorre a $550^{\circ} \mathrm{C}$ (para $\mathrm{P}=5 \mathrm{kbar}$ ). $\mathrm{O}$ processo retrometamórfico foi então paralisado e as associações minerais do metamorfismo regional ficaram preservadas, talvez por insuficiência de fluido aquoso.

A substituição de cianita por andaluzita (Fig. 4) pode ser o resultado de um localizado processo de alívio de pressão para valores de $\mathrm{P}<4 \mathrm{kbar}$ (para $\mathrm{T}=550^{\circ} \mathrm{C}$ ), talvez associado às zonas de cisalhamento mencionadas por Heineck (1997) e Heineck \& Drumond (2004), ao longo das quais posteriormente houve a intensa infiltração de fluidos que propiciaram a formação dos agalmatolitos. $\mathrm{Na}$ Serra do Curral próximo a Ibirité, Quadrilátero Ferrífero, foram descritas feições semelhantes de substituição de cianita por andaluzita, que, no entanto, foram interpretadas como produto de um aquecimento isobárico. Segundo Marshak et al. (1992) e Jordt-Evangelista et al. (1992), na região de Ibirité rochas do Grupo Sabará junto ao embasamento (Complexo Granito-Gnáissico Belo Horizonte) foram aquecidas, sob pressão constante em torno de $3 \mathrm{kbar}$, de cerca de $450^{\circ} \mathrm{C}$ até cerca de $650^{\circ} \mathrm{C}$, em virtude do uplift do embasamento quente, decorrente da extensão crustal transamazônica.

Geração da pirofilita A geração dos agalmatolitos deu-se em evento posterior ao metamorfismo regional de fácies anfibolito baixo, em conseqüência do desenvolvimento das zonas de cisalhamento supostamente transamazônicas (Heineck 1997), nas quais houve pronunciada infiltração de fluidos hidrotermais. Os minerais do protólito que mais nitidamente apresentam essa alteração são andaluzita, cianita e quartzo. A ausência de orientação preferencial planar das palhetas indica que a geração de pirofilita deu-se sem participação de 
pressão dirigida. As reações retrometamórficas de formação de pirofilita e de diásporo (1) a (3), listadas acima, ocorrem entre 350 e $400^{\circ} \mathrm{C}$, para $\mathrm{P}=3,5 \mathrm{kbar}$, isto é, na fácies xisto verde baixo.

Evidências texturais dessas reações podem ser vistas nas figuras 2 e 3 , sendo que os fluidos, de provável natureza aquosa, causariam não apenas a formação de pirofilita e diásporo, mas também transformações químicas das rochas, com lixiviação de elementos mais móveis e concentração residual do alumínio, que é um elemento de mobilidade reduzida. Evidências de que o hidrotermalismo foi acompanhado de modificação química, isto é, de processo metassomático, são as transformações mineralógicas indicadas pelas reações (1), (3) e (5), que envolvem migração de sílica e K. Outra evidência é a presença de turmalinas radiais, preenchendo veios junto com quartzo.

Em resumo, as seguintes etapas levaram à formação do agalmatolito:

1. Geração dos protólitos sedimentar clástico e vulcânico da seqüência vulcanossedimentar do greenstone belt Rio das Velhas.

2. Metamorfismo do tipo barrowiano, indicado pela cianita, em temperaturas na transição da fácies xisto verde a anfibolito, conforme indicado pela paragênese estaurolita e cloritóide nas encaixantes do agalmatolito, paragênese essa estável entre 500 e $550^{\circ} \mathrm{C}$ (Bucher \& Frey 1994). Um alívio de pressão causou a substi- tuição de cianita por andaluzita em $\mathrm{P}<4 \mathrm{kbar}$, talvez decorrente dos eventos deformacionais que culminaram com a geração das extensas zonas de cisalhamento e dos agalmatolitos.

3. Metamorfismo regressivo acompanhado de deformação em condições da fácies xisto verde, levando, entre outras alterações, à cloritização de granada, biotita e estaurolita nos xistos. Nas metavulcânicas houve transformação de plagioclásio em epidoto+albita \pm sericita, sericitação de feldspato alcalino e cloritização dos minerais máficos. Nas rochas francamente aluminosas, houve forte deformação de cianita, andaluzita, quartzo e moscovita e alteração dos dois primeiros minerais em nova geração de moscovita ao longo de fraturas e clivagens. Durante o progresso desse evento de deformação e retrometamorfismo desenvolveram-se as extensas zonas de cisalhamento ao longo das quais são encontrados os corpos de rochas ricas em pirofilita. Nessas zonas, que atuaram como calhas coletoras de fluidos aquosos de natureza hidrotermal, houve reações de formação de pirofilita e diásporo nas rochas aluminosas portadoras de quantidades variáveis de cianita, andaluzita, coríndon, quartzo e moscovita.

Agradecimentos Ao Prof. Dagoberto B. Santos (DEMET/UFMG) pelas análises de MEV; à Lamil Lage Minérios pelas amostras de Pará de Minas, ao Geólogo Paulo Tomedi pelas amostras de Pitangui e Azurita.

\section{Referências}

Bucher K. \& Frey M. 1994. Petrogenesis of Metamorphic Rocks. Springer-Verlag, Berlin, 318 p.

Haas H. 1972. Diaspore-corundum equilibrium determined by epitaxis of diaspore on corundum. Am. Mineral., 57:1375-1385.

Haas H. \& Holdaway M.J. 1973. Equilibria in the system $\mathrm{Al}_{2} \mathrm{O}_{3}-\mathrm{SiO}_{2}-\mathrm{H}_{2} \mathrm{O}$ involving the stability limits of pyrophyllite. Am. J. Sci., 273:449-464.

Heineck C.A. 1997. Geologia e mineralizações do Greenstone Belt Rio das Velhas na região de Mateus Leme, Minas Gerais. Dissertação Mestrado, Instituto de Geociências, Universidade Federal de Minas Gerais.

Heineck C.A. \& Drumond J.B. 2004. Controles tectônicos paleoproterozóicos (?) na constituição dos jazimentos de rochas peraluminosas de Mateus Leme, MG. In: SBG, Cong Bras Geol, 42, Araxá, Resumos, CD-ROM.

Jordt-Evangelista H., Alkmim F.F. \& Marshak S. 1992. Metamorfismo progressivo e a ocorrência dos três polimorfos de $\mathrm{Al}_{2} \mathrm{SiO}_{5}$ (cianita, andaluzita e sillimanita) na Formação Sabará em Ibirité, Quadrilátero Ferrífero, MG. Rev. Esc. Minas, 45(1/2):157-160.

Lara Filho J. 1997. Geologia do Talco e Pirofilita. In: C. Schobbenhaus et al. (eds.) Principais Depósitos Minerais do Brasil. V. 4 Minerais industriais, parte C. Brasília, DNPM/CPRM, cap. 47, p. 592-543.

Leinz V. 1938. Petrografia e gênese dos agalmatolitos de Minas Gerais. In: MORAES L.J. et al. (orgs.) Estudo do agalmatolito. Avulso 32. Rio de Janeiro, DNPM, Serv. Fom. Prod. Mineral, p. 17-22.

Luz A.B., Andrade M.C., Gaspar O.M., Tomedi P. \& Lares C.A.R. 2001. Agalmatolito Lamil. In: J.A. Sampaio, A.B. Luz \& F.A.F. Lins (eds.) Usinas de Beneficiamento de Minérios do Brasil, Rio de Janeiro, CETEM/MCT, p. 201-210.

Luz A.B., Tomedi P. \& Martins R. 2005. Agalmatolito. In: A.B. Luz \& F.A.F. Lins (eds.) Rochas \& Minerais Industriais. Usos e Especificações, Rio de Janeiro, CETEM/ MCT, p. 73-83.

Marshak S., Alkmim F.F. \& Jordt-Evangelista H. 1992. Proterozoic crustal extension and the generation of domeand-keel structure in an Archean granite-greenstone terrene. Nature, 357:491-493.

Moraes L.J. de. 1938. Jazidas de agalmatolito em Minas Gerais. Min. Metal., 3(15):89-96.

Nogueira H. \& Barzaghi L. 1972 Composição mineralógica do agalmatolito de Pará de Minas. Cerâmica, 18(71):371380.

Romano A.W. 1989. Evolution tectonique de la region NordOuest du Quadrilatere Ferrifere - Minas Gerais - Brésil. These de doctorat, Université de Nancy, 259 p.

Manuscrito CSF-04

Submetido em 22 de maio de 2006 Aceito em 30 de março de 2007 